\title{
Developing children and young people's participation in strategic processes: the experience of the Children's Fund Initiative
}

Article

Published Version

Spicer, N. and Evans, R. (2006) Developing children and young people's participation in strategic processes: the experience of the Children's Fund Initiative. Social Policy and Society, 5 (2). pp. 177-188. ISSN 1475-3073 doi: https://doi.org/10.1017/S1474746405002861 Available at https://centaur.reading.ac.uk/24446/

It is advisable to refer to the publisher's version if you intend to cite from the work. See Guidance on citing.

To link to this article DOI: http://dx.doi.org/10.1017/S1474746405002861

Publisher: Cambridge University Press

All outputs in CentAUR are protected by Intellectual Property Rights law, including copyright law. Copyright and IPR is retained by the creators or other copyright holders. Terms and conditions for use of this material are defined in the End User Agreement.

www.reading.ac.uk/centaur 
Central Archive at the University of Reading

Reading's research outputs online 


\title{
Developing Children and Young People's Participation in Strategic Processes: The Experience of the Children's Fund Initiative
}

\author{
Neil Spicer* and Ruth Evans** \\ * Senior Research Fellow, Institute of Applied Social Studies (NECF), University of Birmingham \\ E-mail: n.j.spicer@bham.ac.uk \\ **Research Fellow, Institute of Applied Social Studies (NECF), University of Birmingham \\ E-mail: r.m.evans@bham.ac.uk
}

The extent of children's and young people's participation activities has increased considerably among statutory, voluntary and community sector organisations across the UK in recent years. The Children's Fund, a major government initiative launched in 2000, represents a systematic drive towards promoting children and young people's participation in planning, implementing and evaluating preventative services within all 149 local authority areas in England. Based on research carried out by the National Evaluation of the Children's Fund, this paper explores the experience of Children's Fund partnerships of engaging children and young people in strategic processes.

\section{Policy context}

Since the late 1990s, the UK Government's commitment to increased children's ${ }^{1}$ participation has led to a series of legislative and policy measures to ensure that children have a say about their neighbourhoods, education, health and social services, and other local authority and national policies and services. This is reinforced by the Government's legal responsibilities to fulfil the requirements of the Children Act for England and Wales (1989), the UN Convention of the Rights of the Child (1989) and the Human Rights Act (1998). A recommendation of the Policy Action Team 12 report on Neighbourhood Renewal, for example, was that children should be put: 'at the centre of policies that affect them, organising services round the needs of young people' (Home Office, 2000: 68). Similarly, the cross-departmental Children and Young People's Unit (CYPU) identified children's participation as part of its core strategy in the document Learning to Listen: 'the Government wants children and young people to have more opportunities to get involved in the design, provision and evaluation of policies and services that affect them or which they use' (2001a: 2).

This policy shift prompted a rapid increase in activities related to children's participation in the statutory, voluntary and community sectors across the UK. All central Government departments are required to produce Action Plans detailing their plans to involve children in decision making and many national initiatives and policies and national-level voluntary organisations emphasise children's participation as a key element (DoE, 1995; DfEE, 1999; Barnes et al., 2002). Such policy shifts are accompanied 
by increasing recognition of children's roles as social actors, who actively shape their lives and those of others (James et al., 1998). However, while increasing trends towards 'individualisation' emphasise participation, they also hold children to account for their actions (Such and Walker, 2004). This is manifest in New Labour's rhetoric of 'rights and responsibilities' and increasingly punitive policies towards young people in the youth justice system (Kelly, 2003).

Research and policy documents recognise the political, legal, social and moral reasons for promoting greater children's involvement in their communities (for example, Craig, 2000; Willow, 2002; Sinclair, 2004). Sinclair and Franklin summarise the reasons for involving children as:

to uphold children's rights; fulfil legal responsibilities; to improve services; to improve decisionmaking; to enhance democratic processes; to promote children's protection; to enhance children's skills; to empower and enhance self-esteem. (2000: 1)

Despite widespread commitment to the principle, in practice achieving effective participation in the design, delivery and evaluation of programmes and services is challenging. Indeed, whilst children's participation is widely practiced across the UK, their views have limited impact on public decision making (Kirby and Bryson, 2002); as Prout suggests 'initiatives have remained local, scattered, ad hoc, fragile and experimental' (2000: 309). Indeed, many argue that, in spite of the rhetoric on participation, achieving the goal of meaningful participation of children in policy making remains as elusive as ever (James and James, 2004; Prout, 2000; Hill et al., 2004).

Considerable uncertainty continues to exist about how to involve children in ways that are effective, inclusive, and bring about lasting change. Danso et al. conclude:

despite the expansion of participation activity, there is much still to learn - about making participation inclusive and meaningful to children and young people; about ensuring participation is not simply an end in itself but as a means to change. (2003: 13)

Particular challenges include representing children from diverse socioeconomic and ethnic backgrounds, genuinely empowering children through their involvement and ensuring that they receive adequate feedback about how they influenced policy or practice (Alderson, 1990; Dorrian et al., 2000; Tisdall and Davis, 2004). Critics point to the limited extent to which participation tends to empower children whilst serving and legitimising adult/professionally driven agendas (James and James, 2004). Indeed, it is recognised that a wide range of activities are potentially denoted by the term 'participation' that have different implications for children's empowerment.

Typologies such as Hart's (1992) depiction of different degrees to which children initiate or control the decision-making process (adapting Arnstein's (1969) 'ladder' of participation) are widely cited in the literature, although such hierarchical notions have been questioned. More complex understandings have developed that recognise different ways people may want to participate in different contexts and for different purposes (for example, Shier, 2001). Indeed, three very different rationales for involving children are defined in Learning to Listen: participation leading to better services; promoting children's citizenship and social inclusion; and personal and social education and development 
(CYPU, 2001a). Hill et al. (2004) usefully distinguish 'participation' from 'consultation'. The former denotes children's direct involvement in decision-making; the latter is defined as seeking children's views through various means, typically initiated by decision makers. Throughout this paper we draw on Hill et al.'s definitions when using these terms.

Recent literature emphasises the ways organisational structures and cultures promote or inhibit participation. Kirby et al. (2003) suggest that challenges stem from organisations' 'cultures' of participation and propose two conceptual frameworks. The first defines organisations' orientations: Consultation-focused organisations view children's participation as informing service development; participation-focused organisations involve children in decision making, albeit in time-limited and context specific ways; in child/youth-focused organisations, children's participation is centrally important and children are listened to regarding all decisions affecting their lives. The latter two orientations embrace broad conceptualisations of participation that encompass the empowerment and increased social inclusion of children who participate, although these approaches should not be viewed hierarchically; each may be appropriate within different organisations or settings, or serve different purposes (ibid.). Kirby et al.'s second framework identifies four stages in the process of changing organisations' cultures and institutionalising participation: unfreezing existing attitudes, procedures and styles of working; catalysing change and developing a vision of children's participation; internalising change through communicating and developing a shared vision and understanding of participation; institutionalising change by mainstreaming practice across different organisations (ibid). This paper draws on these frameworks in assessing Children's Fund partnerships' progress in developing children's participation in strategic processes.

\section{Scope and methods}

Launched in 2000, the Children's Fund was established to promote multi-agency working in participative, preventative services for children at risk of social exclusion within each of the 149 English local authority areas. It is part of a long-term strategy aimed at strengthening communities and families as domains in which children develop as healthy, responsible and engaged citizens. The initiative therefore represents a significant commitment to promoting the children's participation agenda nationally by mainstreaming children's participation into local strategic partnership structures, including the emerging Children's Trusts. Each local programme is administered by a strategic partnership board consisting of statutory and voluntary sector representatives.

This paper reflects on Children's Fund partnerships' experiences of engaging children in strategic processes. The range of children's participatory activities adopted is highlighted and the tensions inherent in the Children's Fund initiative that have implications for developing effective participation are explored. We focus on strategic rather than servicelevel participation, since this is where local programmes have tended to encounter most difficulties. Indeed, there are many examples of Children's Fund service providers realising high levels of children's participation (NECF, 2004b). We contrast two different approaches to children's strategic engagement; firstly, consultation of children in the development of Children's Fund programmes; secondly, children's participation in strategic decisionmaking processes. The key strengths and weaknesses of these approaches are highlighted. 
The paper draws on detailed case study research with six Children's Fund partnerships $^{2}$ carried out between January and July 2004 by the National Evaluation of the Children's Fund (NECF) and on analysis of semi-structured interviews with programme managers from all 149 partnerships (summer, 2003). This is part of a wider study that aims to understand the multi-agency structures and processes that support effective participatory, preventative services for children at risk of social exclusion. ${ }^{3}$ In-depth interviews were carried out with 'strategic' stakeholders across the six partnerships consisting of programme managers $(n=6)$, Children's Fund staff such as participation officers, and partnership board members $(n=98)$. Children's Fund project staff $(n=61)$, children $(n=40)$ and parents/carers $(n=35)$ were also interviewed, and additional data were elicited from six focus groups with groups of strategic stakeholders, six with groups of service providers, six with groups of children and parents/carers, and six with all of these groups. These datasets were analysed to form the basis of the conclusions reached in this paper.

\section{Developing children's participation: tensions, compromises and implications}

The participation of children in the development of Children's Fund activity is a key principle of the initiative. The Children's Fund Guidance (CYPU, 2001b) indicates that children should be engaged from the outset of local programmes, they should be actively involved in designing, delivering and evaluating preventative services and an ongoing dialogue with them should be established. Whilst children's participation is a requirement of the Fund, individual partnerships have flexibility to develop innovative forms of participation appropriate to local settings. In practice, the principles of children's participation have been widely embraced across the 149 partnerships and a diverse range of activities has been adopted both in strategic processes and through Children's Fund services. Table 1 illustrates the range of children's participative activities in strategic processes. $^{4}$

Whilst children's participation represents a key principle of the Children's Fund, an overarching tension stemming from the requirements of the initiative makes this difficult to achieve in practice. Strategic stakeholders from case study partnerships widely recognised that investing time and resources in developing mechanisms and capacities is critical in catalysing effective and sustainable children's engagement. These interviewees stated that investment is required to change professional attitudes to children's participation, promote changes in organisational cultures, build capacities and skills within organisations and prepare children to participate through developing their confidence and skills. Strategic stakeholders were, however, preoccupied with the pressures to meet the objectives of the initiative, and indeed the core agendas of the organisations they represent, within short timeframes and with relatively limited resources.

Moreover, whilst the Guidance document establishes the importance of children's participation, it does not clearly articulate the central aims of this area of partnerships' work, nor distinguish between participation and consultation. This is reflected in relatively limited strategic focus and uneven development of participation work within partnerships. Interviews revealed divergent interpretations of the purposes of children's participation between and within partnerships and many strategic and service provider interviewees indicated that they had limited knowledge of children's participation and accepted that 
Table 1 Examples of children's participation in strategic processes: 149 Children's Fund partnerships

\begin{tabular}{|c|c|}
\hline $\begin{array}{l}\text { Informing Children's Fund pro- } \\
\text { gramme development }\end{array}$ & $\begin{array}{l}\text { Consultation events to elicit children's views to inform } \\
\text { strategic planning }\end{array}$ \\
\hline $\begin{array}{l}\text { Partnership management/ } \\
\text { governance }\end{array}$ & $\begin{array}{l}\text { Participation as members of partnership boards/ } \\
\text { forums that feed into partnership boards }\end{array}$ \\
\hline Commissioning services & $\begin{array}{l}\text { Participation in decision making about service } \\
\text { commissioning, including appraisal/selection/ } \\
\text { rejection of funding applications and developing } \\
\text { service level agreements }\end{array}$ \\
\hline Recruitment & Participation in recruitment of Children's Fund staff \\
\hline Allocating resources & $\begin{array}{l}\text { Participation in decision making on spending } \\
\text { budgets/grants according to Children's Fund criteria }\end{array}$ \\
\hline Communication/ promotion & $\begin{array}{l}\text { Involvement in producing newsletters and websites } \\
\text { promoting children's services/issues that concern } \\
\text { children }\end{array}$ \\
\hline $\begin{array}{l}\text { Involvement in wider strategic } \\
\text { processes beyond the initiative }\end{array}$ & $\begin{array}{l}\text { Participation in strategic forums alongside multi- } \\
\text { agency groups; consulting children about their } \\
\text { locality through area-based panels; securing places } \\
\text { for children on local Youth Parliaments }\end{array}$ \\
\hline
\end{tabular}

Source: Interviews with 149 programme managers (summer, 2003) and case study research with six partnerships (January-July 2004).

their partnerships had introduced a range of participation activities without clearly articulating their purposes. A widely held view was that partnerships' participation strategies are the responsibility of particular individuals such as participation officers rather than a focus of dialogue among board members. This was described by some strategic stakeholders as further sidelining children's participation as the focus of partnerships' work (NECF, 2004b).

A further pressure that had implications for the development of children's participation was Central Government's requirement that Children's Fund partnerships allocate 25 per cent of their budgets to activities relating to crime and antisocial behaviour from late 2003. This caused significant tensions between local partnerships' abilities to determine their programmes and Central Government priorities (Morris and Spicer, 2003), and represented a clear signal about the limits of children's involvement in shaping partnerships' work. A number of strategic stakeholders suggested that the rapidly changing policy context and ongoing uncertainty about Children's Fund budget allocations compromised levels of participation and hindered effective planning of these activities. Mindful of these pressures, partnerships have compromised what were viewed as ideal forms of participation with more realistic expectations about the activities they adopt and the numbers of children they engage within available time and resources, whilst fulfilling the initiative requirements on children's participation. The next sections explore two contrasting approaches adopted by partnerships in developing children's participation in strategic processes and consider their strengths and weaknesses. We refer to these approaches as quantitative and qualitative participation. 


\section{Quantitative participation: consultation in the development of Children's Fund programmes}

Strategic stakeholders and service providers perceived children's participation principally in terms of consultation to inform the development of partnerships and services, suggesting that the case study partnerships are predominantly consultation-focused organisations (using Kirby et al.'s 2003 framework). This was rationalised as enabling partnerships to respond to children's views and develop services based on their articulated needs. As a partnership board member commented: 'If effective services are the desired goal then stakeholders must listen to children and young people and their families.' By 2003, all case study partnerships reported that they had undertaken consultation exercises or were developing mechanisms to enable consultation to inform their programmes and services. However, the extent to which participation was equated with consultation varied between case study partnerships. At the strategic level, two partnerships focused on quantitative participation; relatively large numbers of children's views were elicited through one-off consultation events, and their involvement was seen as informing partnerships' development through participation officers who represented their views to partnership boards. Both partnerships also worked on the strategic development of children's participation through multi-agency structures at authority-wide levels, rather than directly involving children in management or in strategic decision-making processes.

Within strategic stakeholders and service providers' accounts there appears to be an implicit hierarchy between consultation and participation; whilst a number of partnerships have aspired to involve children in decision-making processes, in practice they developed consultation activities since the approach was seen as quicker and less complex to implement than involving children directly in strategic decisions whilst fulfilling the initiative requirements. The extent to which partnerships have developed children's participation rather than consultation has been influenced by different degrees of apprehension or resistance from some partner organisations, although considerable variations in organisations' levels of engagement exist, highlighting the problems of developing focused, coherent approaches to children's participation in multi-agency settings. Involving children in partnership management in particular was viewed as challenging orthodox, professionally dominated approaches to decision making, and potentially implied considerable shifts in power and responsibility. Some strategic stakeholders felt that children's participation in complex, strategic processes was inappropriate; hence, they had elected to consult children rather than involve them directly in decision making. As a member of a partnership board, commented:

If you do it right, you're going to be challenged and the structures are going to be challenged ... I would hazard a guess that there would be a lot of resistance, good god, yes. A lot of resistance to consulting ... adults, never mind young people, so yes, it's just a guess, yes, there'd be a lot of resistance.

Such apprehensions were described by some strategic stakeholders and service providers as stemming from limited knowledge about, and experience of children's participation among many organisations prior to the Children's Fund, rather than deep-rooted resistance to the concept. Developing a shared understanding of the issues was therefore perceived as critical for promoting children's participation within partnerships and across local 
authority areas. Efforts to promote a coherent vision by some partnerships were felt to be yielding results; participation officers were regarded as important in 'championing' such visions, although it was recognised that planning this area of work required considerable time and resources. As one strategic interviewee suggested, 'the preparation to get... meaningful involvement from children is time-consuming. It also takes time to move people to a place where they value that involvement. The cultural shift takes a while.' Using Kirby et al.'s (2003) framework, it appears that some partnerships are working on unfreezing existing attitudes and catalysing change through champions of participation to develop shared visions of children's participation.

An advantage of quantitative participation is its potential to be relatively democratic through seeking the views of large numbers of children from relatively diverse groups in contrast to qualitative participation (discussed below). However, the extent to which partnerships actually drew on children's views as the basis for strategic decision making varied. Among case study partnerships, there were few examples of mechanisms for taking forward children's views, limited sustained involvement of individual children and limited feedback about the impact of their participation. Such an approach to children's engagement is often criticised in the literature as tokenistic, disempowering and may disengage children from participative processes (Dorrian et al., 2000; Tisdall and Davis, 2004). Indeed, children's perspectives of participation differed considerably from strategic stakeholders rationales for consultation, highlighting the extent to which consultation serves adults' rather than children's agendas. Children participating in various elements of Children's Fund programmes described their participation experientially as increasing their confidence, helping develop interpersonal and transferable skills and providing positive experiences of communicating with adults, notions that accord with the CYPU's personal and social education and development rationale for children's participation (2001a). For example, one young person who had been involved in staff recruitment and other activities said:

this has given me more confidence... because I used to be quite shy and now I don't mind talking in public ... I used to, like I would rather sit in a corner alone and read a book but now I would rather shout out and talk to people and stuff because of doing the interviews and stuff has made me want to talk more...

\section{Qualitative participation: children's direct engagement in decision-making processes}

The remaining four partnerships, whilst viewing participation as informing their programmes/services, also saw participation as fulfilling children's rights to participate in decisions affecting them, as empowering children and helping to prevent their social exclusion, perspectives that correspond to the promoting citizenship and social inclusion and personal and social education and development rationales for children's participation (CYPU, 2001a). As a partnership board member said: 'It's positive experiences that they wouldn't otherwise have had and for them to get the notion that they are important and their opinions do matter.' Reflecting this rationale, these partnerships have developed a number of mechanisms for involving children directly in strategic decision making, including involvement in partnership board meetings, children's forums feeding into partnership boards and subgroups for commissioning services or staff recruitment. In one 
partnership, in which a rights-based rationale for children's participation was strongly articulated, children were engaged in a service delivery model of participation that feeds into strategic processes. Strategic interviewees from these partnerships reported considerable success; board members from one partnership, for example, suggested participants in a children's forum had contributed to 'real and meaningful' decision making for staff recruitment, appraising funding applications and allocating resources. In another partnership, children involved in a commissioning subgroup were described by strategic stakeholders as playing a key role in deciding which commissioning model would be both effective and inclusive. Although these partnerships remain principally consultation-focused organisations, they are also becoming participationfocused organisations, albeit not consistently across all strategic and operational levels of their programmes.

These decision-making forums, however, generally involved small numbers of children (often five or less), who tended to have relatively long-term participation; hence we refer to this approach as qualitative participation. Whereas consultation tends to serve adults' agendas, this approach appears to correspond to children's agendas for participating, as well as being more empowering to them (as articulated above). Nevertheless, many strategic stakeholders were conscious of potential tensions between adult-driven agendas and their ability to act on children's articulated views. Pressures from Central Government, such as the ' 25 per cent' requirement, were seen as limiting the extent to which children could determine local programmes' directions. In this context, strategic stakeholders and service providers stressed the importance of articulating to children the parameters of their influence on decision making and thus to avoid potential disappointment or disillusionment if their views were not acted upon or conflicted with the adult-driven policy agenda from Central Government.

In these partnerships, there was commitment to involve diverse groups of children, representing different ethnicities, genders, ages, socioeconomic and home backgrounds and geographical areas. There was also some, albeit limited, acknowledgement that different approaches may be needed to engage different groups, and that children may articulate differing interests and needs. This aspiration was compromised by the need for significant commitment of time and resources to involve children, particularly those perceived as difficult to engage such as younger children and children with complex needs, including learning difficulties, challenging behaviour and autism. Issues of representation were seen as particularly acute when adopting qualitative approaches to participation that may make more demands on children and by definition involve fewer children overall. Despite commitment to be inclusive, and one partnership had invested time and resources in supporting children with learning and behavioural difficulties to participate in strategic processes, strategic stakeholders acknowledged that mainly older, white, middle-class children, who did not necessarily represent other children's views, were involved in qualitative participation. This issue has been highlighted across other Children's Fund programmes (Craig et al., 2004). Moreover, some strategic stakeholders were sceptical about expecting a regular, 'elite' group of children to represent other children, since this might lead to what some called 'consultation fatigue', as well as excluding others from participation opportunities, which may be empowering and enhance their social inclusion. Hill et al. (2004) usefully differentiate between two ways of thinking about 'representation': the first being in a 'statistical' sense, where views are seen as generalisable across a population, and in a 'political' sense, where participants 
are seen as voicing the views of others. Whilst this distinction tended not to be articulated by stakeholders, quantitative participation appears to most closely relate to statistical representation, whilst qualitative participation corresponds with the notion of political representation.

Strategic stakeholders highlighted that considerable time, energy and resources were needed to develop environments that promote children's effective engagement in decision-making processes. It was accepted that increasing the inclusiveness of meetings would result in considerable changes in the ways partnerships worked. As an interviewee explained, board members now come to meetings 'with a different head

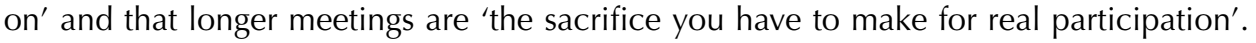
Key conditions described as facilitating children's effective participation include using accessible language, avoiding professional meeting formats and holding meetings in informal settings. An interviewee commented on early, unsuccessful attempts to engage children in conventional meeting formats:

Children hated it. It was adult terms and it was adult times and it was adult business, and no matter how much you tried to make it child-friendly there was still the business that you had to do that the children found boring.

The three partnerships in which children participated in strategic decision-making processes adopted a range of means to ensure that the language, structure, and meeting environments were engaging and inclusive. One partnership promoted accessible, jargonfree language through adopting a system whereby any board member or child could hold up a 'yellow card' if they felt inaccessible language had been used. During board meetings, pictorial means were used to simplify, clarify and summarise concepts and ensure that children understood the implications of their decisions. The participation officer had an important role in actively drawing participants into discussions in ways that they could relate to. Other ways the same partnership had sought to engage children included creating informal meeting spaces and providing children with drawing materials and other activities. Meetings were arranged at times that fitted appropriately around the school day and were generally longer than orthodox meeting styles to ensure that issues were fully understood by children. It was acknowledged by some strategic stakeholders that different approaches may be needed to engage children from more marginalised groups. For example, participation workers from a partnership that had engaged children with learning and behavioural difficulties in strategic decision making highlighted the need for extensive preparation and ongoing one-to-one support to encourage and sustain children's participation. Organising longer sessions during school holidays provided more time for fun activities in addition to actual decision making than more time-limited after-school sessions, a format that was more appropriate for children with learning and behavioural difficulties.

\section{Conclusions}

As a guiding principle of the Children's Fund, children's participation has been widely embraced across local partnerships. However, case study partnerships can be broadly characterised as consultation-focused organisations, although some appear also to be 
participation-focused organisations (using Kirby et al.'s 2003 framework). Case study partnerships are currently working on unfreezing existing professional attitudes, procedures and styles of working, catalysing change and starting to develop visions of children's participation through partnership working. Hence, whilst participation is widely viewed as being analogous to consultation, in some cases, participation is described as directly beneficial to children through providing activities that are potentially empowering and help to prevent social exclusion. It was evident, however, that there was considerable variation in the degree to which different partner organisations were willing to embrace children's participation in strategic processes; those with limited histories of children's participation tended to be hesitant in embracing the agenda. This underscores the need for partnerships to develop clearly articulated visions of the purposes of participation and to provide spaces for debate, reflection and learning in relation to these issues. Only then will partnerships be able to move towards the goals of internalising shared visions and understandings of participation and institutionalising participation by mainstreaming practice (ibid.).

An overarching tension stems from the requirements of the Children's Fund; partnerships must balance the requirement to rapidly deliver their programmes with relatively limited resources, with the need to invest considerable time and resources to achieve effective children's participation. In this context, partnerships have compromised, often through making a choice between quantitative and qualitative approaches to participation. Both approaches have advantages and are appropriate in different contexts for different purposes. Both are also problematic; the former tends to serve adults'/professionals' policy-driven agendas and offers limited personal benefits to those participating. Whilst the latter potentially brings about greater degrees of empowerment to children as individuals and may correspond with their agendas for participating, the approach can exclude children from diverse backgrounds.

Indeed, ensuring children involved in participation activities represent different genders, ethnicities, ages, abilities, socioeconomic and home backgrounds and geographical areas is an ongoing challenge. Despite some examples of effective engagement of children of different ages and levels of needs in strategic decision-making, partnerships continue to experience difficulties in engaging large numbers of children directly in strategic processes, as well as problems including children who are perceived as difficult to engage. This means that partnerships have not yet brought about meaningful shifts in the balance of power from adults/professionals to the diverse range of children who are experiencing significant disadvantage and exclusion. Whilst the Children's Fund initiative represents a relatively systematic approach to promoting children's participation across England, sustained, long-term commitment is required at both national level and through local multi-agency structures, particularly Children's Trusts and other structures of integrated children's services, if the objective of effective and sustained children's participation and consultation is to be achieved.

\section{Notes}

1 The term 'children' is used is this paper to denote children and young people under 18 years of age. The Children's Fund targets children aged 5-13 years. 
2 The six case studies represent regional spread and type of local authority including rural, urban, unitary, two-tier and metropolitan.

3 More detailed descriptions of Children's Fund activities are provided elsewhere (Morris and Spicer, 2003; NECF, 2004a, 2004b, 2005; Craig, McNamee and Wilkinson, 2004).

4 Children's participation at project level is discussed in Morris and Spicer (2003) and NECF (2004b).

\section{References}

Alderson, P. (1990), Choosing for Children: Parents' Consent to Surgery, Oxford: Oxford University Press.

Arnstein, S. (1969), 'The ladder of citizen participation', Journal of the American Institute of Planners, 35, 2, 216-224.

Barnes, M., Matka, E. and Sullivan, H. (2002), Building Collaborative Capacity Through Health Action Zones: The Lambeth, Southwark and Lewisham Experience, Birmingham: National Evaluation of Health Action Zones, University of Birmingham.

Craig, G. (2000), What Works in Community Development with Children? Ilford: Barnardo's.

Craig, G., McNamee, S. and Wilkinson, M. (2004), Views on the Children's Fund from Children's Society Projects, London: The Children's Society.

CYPU (2001a), 'Learning to listen: core principles for the involvement of children and young people', Department for Education and Skills, Annesley.

CYPU (2001b), Children's Fund Guidance, London: Department for Education and Skills.

Danso, C., Greaves, H., Howell, S., Ryan, M., Sinclair, R. and Tunnard, J. (2003), 'The involvement of children and young people in promoting change and enhancing the quality of social care', National Children's Bureau Research Report, London.

Department for Education and Employment (1999), The National Curriculum for England: Citizenship: Key Stages3-4, London: Department for Education and Employment.

Department of the Environment (1995), Involving Communities in Urban and Rural Regeneration: A Guide for Practitioners, London: Department of the Environment.

Dorrian, A., Tisdall, K. and Hamilton, D. (2000), Taking the Initiative: Promoting Young People's Participation in Public Decision Making in Scotland, London: Carnegie Young People Initiative.

Hart, R. (1992), 'Children's Participation: From Tokenism to Citizenship', UNICEF Innocenti Essays 4.

Hill, M. Davis, J., Prout, A. and Tisdall, K. (2004), 'Moving the participation agenda forward', Children and Society, 18, 77-96.

Home Office (2000), Social Exclusion Unit Report of the Policy Action Team 12: Young People, London: HMSO.

James, A. and James, A. (2004), Constructing Childhood: Theory, Policy and Social Practice, Basingstoke: Palgrave MacMillan.

James, A., Jenks, C., and Prout, A. (1998), Theorizing Childhood, Cambridge: Polity Press

Kelly, P. (2003), 'Growing up as risky business? Risks, surveillance and the institutionalised mistrust of youth', Journal of Youth Studies, 6, 2, 165-180.

Kirby, P. and Bryson, S. (2002), Measuring the Magic? Evaluating and Researching Young People's Participation in Public Decision Making, London: The Carnegie United Kingdom Trust.

Kirby, P., Lanyon, C., Cronin, K. and Sinclair, R. (2003), 'Building a culture of participation: involving children and young people in policy, service planning, delivery and evaluation', Research Report, Department for Education and Skills, London.

Morris, K. and Spicer, N. (2003), Early Messages for Developing Practice, London: Department for Education and Skills.

NECF (2004a), Collaborating for the Social Inclusion of Children and Young People, London: Department for Education and Skills.

NECF (2004b), Children, Young People, Parents and Carers' Participation in Children's Fund Case Study Partnerships, London: Department for Education and Skills. 
NECF (2005), Prevention and Early Intervention in the Social Exclusion of Children and Young People, London: Department for Education and Skills.

Prout, A. (2000), 'Children's participation: control and self-realisation in British late modernity', Children and Society, 14, 305-319.

Shier, H. (2001), 'Pathways to Participation: opening, opportunities and obligations. A new model for enhancing children's participation in decision - making in line with Article 13.1 of UNCRC', Children and Society, 15, 107-117.

Sinclair, R. and Franklin, A. (2000), 'A quality protects research briefing: young people's participation', Research in Practice and Making Research Count, Department of Health, London.

Sinclair, R. (2004), 'Participation in practice: making it meaningful, effective and sustainable', Children and Society, 18, 106-118.

Such, E. and Walker, R. (2004), 'Being Responsible and Responsible Beings: Children's Understanding of Responsibility', Children and Society, 18, 231-242.

Tisdall, E. and Davis, J. (2004), 'Making a difference? Bringing children's and young people's views into policy-making', Children and Society, 18, 131-142.

Willow, C. (2002), Participation in Practice: children and young people as Partners in Change. London: The Children's Society. 